\title{
Future imaginaries in the making and governing of digital technology: Multiple, Contested, Commodified
}

\author{
Astrid Mager \& Christian Katzenbach
}

Preprint (March 2020) forthcoming in New Media \& Society:

Mager, A. \& Katzenbach, C. (2020). Future imaginaries in the making and governing of digital technology: Multiple, Contested, Commodified. New Media \& Society. Online First. doi: 10.1177/1461444820929321.

\begin{abstract}
Visions of the future are omnipresent in current debates about the digital transformation. This introductory article and the full special issue are concerned with the function, power, and performativity of future visions and how they relate to the making and governing of digital technology. Revisiting existing concepts, we particularly discuss and advance the concept of sociotechnical imaginaries. In difference to ephemeral visions and partisan ideas, imaginaries are collectively held and institutionally stabilized. Nonetheless, we hold that they are multiple, contested and commodified rather than monolithic, linear visions of future trajectories enacted by state actors. Introducing and summarising the articles of the special issue, we conclude that imaginaries are increasingly dominated by technology companies who not only take over the imaginative power of shaping future society. They also partly absorb public institutions' ability to govern these very futures with their rhetoric, technologies and business models.
\end{abstract}

In January 2018, the software platform Blockchain announced its partnership with the cryptocurrency dealer SFOX that enables US-American users to easily buy and sell digital assets. In their self-description, they straightforwardly promised: "We are on a mission to build a more open, accessible, and fair financial future, one piece of software at a time" ${ }^{\prime i}$. Similarly, the self-driving car company Waymo (a subsidiary of Google's parent company, Alphabet Inc.) expressed their mission as follows: "Imagine if everyone could get around easily and safely, without tired, drunk or distracted driving" $i i$. These two quotes illustrate how software developers and technology companies dig into the rich pool of cultural norms, visions, and values to support digital tools and artefacts. In a similar vein, policy and public institutions promote their roadmaps, rules and regulations. The European Commission, for example, promotes its General Data Protection Regulation (GDPR) as "an essential step to strengthen citizens' fundamental rights in the digital age and facilitate business by simplifying rules for companies in the Digital Single Market." "iii Such evocations of possible or fantastic, desirable or dystopian futures are necessarily genuine sociopolitical processes with material consequences in the present. To make decisions in the present, we need future prospects, be they realistic or fantastical, for guidance and orientation. The future is then not only imagined, but it is also very concretely constructed, made and unmade in different constellations and contexts. By guiding the making of things and services to come, imaginations of the future are co-producing the very future they envision. Hence, future visions are performative. 
This special issue is concerned with the function, power, and performativity of future visions and how to relate it to the making and governing of digital technology. It traces how future visions emerge in different cultural settings, how they gain strength across time, space and sectors, how they compete and complement each other, and how they struggle over dominance when alternative futures appear on the horizon. The special issue also asks how future visions materialize in the shaping of digital technology. How do they become productive in the actual construction of the future? The contributions can be roughly divided into three groups of articles: One set of articles analyzes the emergence of corporate sociotechnical imaginaries articulated by powerful actors such as Facebook's CEO Mark Zuckerberg and other actors in power. A second group of papers deals with the transformation of global, transnational imaginaries into local contexts, scientific practice and internet infrastructure. And a final group of contributions focuses on the role of counter-imaginaries, participatory interventions and our own choice of words in imagining and creating alternative futures. Taken together, these articles provide a rich repertoire of situated case studies and in-depth analyses of future imaginaries in the making and governing of digital technologies, infrastructures and social practices.

\section{Studying the nexus of discourse, technology and politics}

Narratives of the future and their relation to the present is a long-standing theme in the social sciences and humanities. Scholars from the sociology of science and technology, from media and communications, and from linguistics have developed a vast body of notions that help to identify, describe and scrutinize how future visions are emerging as relevant narratives, are mobilized by stakeholders with vested interests and are then, in turn, informing and shaping practices in the present. In the sociology of futures, scholars have proposed notions such as "expectations and stories about the future" (Van Lente and Rip 1998; Van Lente 2012) and "contested futures" (Brown, Rapport and Webster 2000, Brown and Michael 2003). In research that studies communities of practice as cradles of future technology, scholars have scrutinized the "vanguard visions" (Hilgartner 2015) of these pioneers. With more attention to language and discourse, particular as represented in the media, scholars in linguistics, media and communications and the social sciences have looked at "metaphors" (Lakoff and Johnson 1980), "myths" (Mosco 2005) and their relation to technology (Wyatt 2004; Katzenbach/Larsson 2017) and more broadly at "discourse" (Hajer 1995, 2006) or "frames" (Goffman 1974) and their constructive power. In broader social theory, Arjun Appadurai, Charles Taylor, George E. Marcus and Patrice Flichy have established the notions of "social imaginary" (Appadurai 1996; Taylor 2004), technoscientific imaginaries (Marcus 1995) and "imaginaire" (Flichy 2007). Additionally, there is a substantial body of literature that looks at the conjunction with technology and science (cf. McNeil et al. 2016 for an overview). Most notably, Robin Mansell (2012) mobilizes the notion of imaginaries to understand the institutionalization of the internet in contemporary society.

In research that is concerned with the political quality of technology and imaginaries, the concept of "sociotechnical imaginaries" (Jasanoff and Kim 2009, 2015) has become one of the most prominent. In recent years, this concept has become a popular analytical tool to describe and understand the coproduction of technoscientific projects, social constellations and politics. It serves as a lens through which the interplay and mutual shaping of science, technology and society can be identified and analyzed. In the initial definition, Jasanoff and Kim positioned sociotechnical imaginaries (referred to as SIs in the following) as an analytical device that captures the "collectively imagined forms of social life and social order reflected in the design and fulfillment of nation-specific scientific and/or technological projects" (Jasanoff and Kim 2009, 120). This initial understanding of SIs strongly focused on how nation states, governmental actors and public institutions envision and enact technoscientific developments (Jasanoff and Kim 2009). This restricted focus on state actors has become an object of critique 
recently. Scholars have highlighted that imaginaries are also articulated and enacted by corporate actors, civil society, research communities and other organized groups in processes much more complex and non-linear than envisaged in the original concept (Felt and Öchsner 2018, Olbrich and Witjes 2017, Lehtiniemi and Ruckenstein 2019, Mager 2018, Jasanoff/ Kim 2015). In turn, Jasanoff herself has argued that the concept needs to be "refined and extended in order to do justice to the myriad ways in which scientific and technological visions enter into the assemblages of materiality, meaning, and morality that constitute robust forms of social life" (Jasanoff 2015a: 4). In the introduction to her recently edited volume (Jasanoff/Kim 2015), she thus broadened the definition of SIs to encompass "collectively held, institutionally stabilized, and publicly performed visions of desirable futures, animated by shared understandings of forms of social life and social order attainable through, and supportive of, advances in science and technology." (Jasanoff 2015a, 4)

\section{Sociotechnical Imaginaries: Multiple, Contested, Commodified}

This special issue further advances this elaboration of the concept in the context of digital technologies. It brings together a set of empirical case studies and theoretical contributions showing that sociotechnical imaginaries often appear to be multiple, contested and commodified rather than being monolithic, linear visions of future trajectories that are primarily enacted by state actors. Not only state actors and governments unfold their power to imagine, govern and program digital innovations and related social practices, but also big technology companies, influential CEOs, corporate communications, technology events, industry consultants, research groups and grassroot activists.

Sociotechnical imaginaries are multiple. The concept of sociotechnical imaginaries refers to "collectively held and institutionally stabilized" (Jasanoff 2015a: 4) visions of the future - that is to say, not every articulation of possible futures constitutes a sociotechnical imaginary. It needs resonance among collectives, the allocation of resources and the adoption into practices of making, governing and doing to become institutionalized. Restricting the notion to ideas that are soundly embedded in cultures, institutions, and materialities is necessary in order to retain its analytical value and differentiate it from notions such as ideas, frames and visions, which are rather agnostic about their footprint beyond the discursive dimension. Yet, the initial monolithic picture of SIs has proven to be misleading. There are almost always multiple imaginaries in circulation that are more or less powerful. While the widely referenced study on visions of nuclear energy in the USA and South Korea seemed to indicate that there is a single imaginary in each country that changes and adapts (Jasanoff/Kim 2009), numerous studies on sociotechnical imaginaries demonstrate that the circulation of single imaginaries is the exception, not the rule. For example, scholars who have analyzed sociotechnical imaginaries in EU digital policy have identified different imaginaries in the context of search engines (Mager 2017) and big data solutions (Rieder 2018) and showed how these imaginaries travel into and transform in national sociopolitical contexts and communities of practice (Mager 2018). In the context of European search engine policy and data protection Mager (2017: 256) concludes "sociotechnical imaginaries should not be seen as monolithic or stabilized, but rather as multifaceted and dynamic". Studying visions of digital technologies thus also implies tracking the trajectories of multiple imaginaries and their relation to one another.

Sociotechnical imaginaries are contested. When imaginaries are multiple and not singular, they often appear to be not consensually defined. The future is, as Brown, Rappert, and Webster (2003: 3) write, "a contested object of social and material action". Actors at individual and institutional levels - framed by their own sociocultural contexts, guided by their respective interests, and equipped with differing resources - construct future expectations and strive to translate these into encompassing and sustaining imaginaries, intentionally or not. Some of the visions and imaginaries might run peacefully in parallel, while others may contest each other 
and seek for dominance or resistance (Jasanoff 2015b: 329). Sang-Hyun Kim's detailed account of imaginaries that challenged the official visions of the South Korean state in nuclear power, biotechnology and food safety offers a prime example of the contestation of dominant imaginaries (Kim 2015). Lehtiniemi and Ruckenstein (2019) illustrate the contestation of dominant imaginaries in the making and governing of digital technology in their study on data activism in Denmark: here, bottom-up initiatives not only seek to shape future visions of the internet but work to materialize this vision into technological infrastructure. Similarly, Barker's reconstruction of hobbyists and research networks in Indonesia shows how alternative imaginaries challenge incumbent institutions and material infrastructure (Barker 2015). Mansell's (2012) sweeping account of imaginaries of the internet also shows how two conflicting imaginaries have shaped the design and governance of our digital networks. The study of imaginaries of digital technology thus often involves the investigation of more or less explicit contestations and struggles over dominance.

Sociotechnical imaginaries are commodified. In this process of negotiating the future, it is often not state actors that act as primary agents of powerful imaginaries, as originally held in the concept of SI, but corporate players. "Multinational corporations increasingly act upon imagined understandings of how the world is and ought to be, playing upon the perceived hopes and fears of their customers and clients and thereby propagating notions of technological progress and benefit that cut across." (Jasanoff 2015a: 27) Especially in the context of digital technologies, this discursive embedding of technological developments and commercial products is pervasive. Entrepreneurs routinely attire their products and services in utopian visions of the future, narratives of community-building, and the promise of technological fixes for social problems (Turner 2006, Katzenbach 2019). Tech companies have adopted notions such as "sharing" (John 2015, 2017) and "community" to propel imaginaries of new socioeconomic orders that comfortably accommodate their business interests and commercial products (Srnicek 2016). Scholars have further pointed to the importance of corporate imaginaries in the context of RFID tagging (Felt and Öchsner 2018) and commercial satellite imagery (Olbrich and Witjes 2017). Thus, the circulation of imaginaries is often not motivated and propagated by state actors and their interests, but by commercial actors' assumptions about technology that directly shape the design of their products.

\section{Hitting the Ground: How Imaginaries Matter in the Actual Making and Governing of Digital Technology}

Contemporary sociotechnical imaginaries are multiple, contested and commodified. By foregrounding these three aspects, this special issue expands and advances the ongoing conceptual debate about the role of discourse and visions in shaping the emerging digital society in general, and contributes to the elaboration of the concept of sociotechnical imaginaries in particular. The different case studies yield fine-grained analyses showing how global sociotechnical imaginaries and grand visions solidify and institutionalize: how they get embedded and materialize in digital technology and local practices. The articles draw their inspirations from different research traditions including sociology, new media studies, science and technology studies, future studies, critical data studies, and critical pedagogy as well as feminist practices of speculation. Methodologically, they use a mix of methods and empirical data ranging from qualitative ethnography, interviews, discourse analysis, and participatory interventions to quantitative analyses of heterogeneous documents, mailing lists and media materials. Consequently, they provide a rich picture of how future imaginaries, visions and values gain ground and settle in internet architecture and governance bodies (ten Oever), social media platforms (Haupt), digital payments (Mützel), augmented reality (Liao/Iliadis), brain models (Mahfoud), start-up cultures (Hockenhull/Cohn), alternative technologies (Kazansky/Milan), and, ultimately, in people's minds (Markham) and our own metaphorical 
language (Wyatt). By specifically looking at research communities, software practices and industry gatherings, the authors shed light on the complex processes and practices of translating and transforming future imaginaries into today's technologies and mundane practices.

By bringing together future imaginaries of various kinds and scales, the contributions open up the view on how big technology companies make use of future imaginaries to expand their “technological zones" (Barry 2001, 2006, Mager 2017) going beyond geopolitical and cultural boundaries. But they also demonstrate how bottom-up imaginaries, speculative interventions and - ultimately - our own choice of words as vigilant researchers can help to push back and create alternative digital futures. Observing, and partly participating in, actual practices and projects makes us understand how tensions, ambivalences, and ruptures emerge when future visions are encoded in technology and how scale matters when it comes to competing imaginaries, hegemonic narratives and counter-cultural voices.

\section{Contributions to this Special Issue}

For this special issue, we deploy this question of scale as the organizing principle. Thus, the contributions are sorted along the axis of scale. We start with the corporate visions dominating contemporary technology developments and end with counter-imaginaries and critical interventions emerging on the horizon. The first group of articles investigates the emergence of corporate sociotechnical imaginaries articulated by powerful individuals such as Mark Zuckerberg and other industry actors. The second set of articles deals with the transformation of global, transnational imaginaries into local contexts, scientific practices, and internet infrastructure. And a final group of contributions focuses on the role of smaller counterimaginaries, participatory interventions, and our own choice of words in imagining and creating alternative futures.

\section{1) Corporate sociotechnical imaginaries}

The special issue opens with a contribution by Joachim Haupt analyzing Mark Zuckerberg's "discursive construction of a better world". Drawing on a discourse analysis of Zuckerberg's public communications and working with the notion of "corporate sociotechnical imaginary" the article analyzes how Facebook's future imaginaries change over time, how central discursive elements like "global connectivity" or "global community" are substantiated, and how normative notions help to support these imaginaries. This fine-grained empirical work allows the author to reconstruct how the discursive work of a single actor solidifies over time in corporate communications, goals and technologies and how it is strategically used to legitimize corporate action and unleash its power in broader discursive struggles. The author concludes by arguing that Facebook can be seen as a paradigmatic case illustrating how "prophetic corporations" seek to provide future visions of a better world in order to guide and legitimize their own digital technologies and business practices.

The second article, written by Tony Liao and Andrew Iliadis, investigates ten years of past futures in the "Augmented Reality (AR) Hype Cycle". Building on "the sociology of futures" and a comparative analysis of macro and micro level futures, the article maps the interrelationships of different future imaginaries across the stages of the Gartner hype cycle. By juxtaposing ethnographic fieldwork at global AR conferences with an analysis of an AR media database, the authors can track shifts in futures over time and understand the broader deployment of futures in the shaping of a technology as it enters different phases. There are few studies that empirically bring together the imaging of futures and the making of future and relate these to each other. This accomplishment positions Liao and Iliadis's article as a particularly important contribution to understanding the dynamics in emerging technologies and the multiple futures at stake. 
The last article dealing with corporate imaginaries, by Sophie Mützel, focuses on future imaginaries of digital payments. Having analyzed a decade of industry reports on digital payments the author identifies three imaginaries or "stories of the future" that are shaping the banking and payment industry: data monetization, the growth of digital payments, and the payment experience. This analysis enables the author to retrace the platformization of the financial industry and to show how digital payments and its narratives have restructured financial services towards a "re-personalization of money". It summarizes that digital payments play a central role in the current economic transformations. This development is led and promoted by global technology companies that excel in the tracking, production, categorization, and classification of digital data.

2) Translation of global imaginaries into local contexts, scientific practice and infrastructure

The next set of articles begins with a paper by Michael Hockenhull and Marisa Leavitt Cohn who focus on how global "sociotechnical imaginaries" of digital technologies get translated locally into the context of the Danish welfare state. Drawing on ethnographic fieldwork of Danish technology events the contribution conceptualizes "hot air" as a lens through which the dynamics of hype and critique in performing and sustaining sociotechnical imaginaries can be described. This analysis shows how global sociotechnical imaginaries are performed, contested and translated into local contexts through promotional talks, conferences and events. The contribution demonstrates convincingly how talk about futures can be "simultaneously vacuous and productive". It is in this process of translating abstract imaginaries and fantastic hype into local practices that the notion of "hot air" helps to understand how grand visions are specified, transformed and made material, as the authors conclude.

The next article, written by Tara Mahfoud, analyzes "competing visions" of how brain models should be built and research communities should be organized in the context of the Human Brain Project (HBP). Based on multi-sited ethnographic fieldwork in Austria, France, Germany, the UK and the HBP headquarter in Switzerland the article relates how the conflict over this massive project's goal to build a model of the brain was entangled with questions of research infrastructure, international collaboration and even the identity of the European Union. She concludes that the initial vision of the HBP was not abandoned because it proved to be scientifically or technologically untenable, but because the initial vision did not meet with the identity of the research community nor of the European Union at large as unity in diversity. With that analysis, Mahfoud provides a striking example of how future visions get embedded in scientific concepts and research infrastructures.

The last article of this sub-set is written by Niels ten Oever and examines the internet architecture imaginary that guides the co-production of policy and technology tracing back to the early phases of the internet. Using a combination of quantitative and qualitative methods the article shows how the internet architecture's "sociotechnical imaginary" and its technical affordances got reconfigured over time following the commercialization and privatization of the internet. It argues that the imaginary is anchored in the principles of end-to-end, permissionless innovation, and openness and is operationalized through a process of coproduction. While the initial internet architecture imaginary and its self-regulatory governance model are still professed by the Internet Engineering Taskforce, ten Oever carves out how economic drivers have increasingly undermined the design goals of the internet architecture and prioritized economic interests. As a result, the study demonstrates that the long-time prevailing internet imaginary as decentralized, end-to-end network affording permisionless innovation and openness for everyone has become out of touch with the reality of a thoroughly commodified and increasingly centralized internet.

3) Alternative imaginaries, interventions and our own choice of words 
The last group of articles deals with initiatives and strategies to counter this development of commodification and corporatization, focusing on alternative imaginaries and critical interventions that seek to contribute to more just digital futures. The article by Becky Kazansky and Stefania Milan analyzes civil society's responses to dominant imaginaries of datafication and their associated harms and risks. Using an ethnographic case study approach this article investigates how "counter-imaginaries" of datafication are enacted in three open source software projects. Having investigated a secure desktop ecosystem, an internet of Things awareness device and a critical response to the facial recognition hype, the authors show how grassroot initiatives try to ,bulwark autonomy, increase agency and provoke critical inquiry into new ways of being and doing amidst the threats of pervasive datafication". Despite their smallness, the authors convincingly argue, these sociotechnical interventions matter. And indeed, such alternative imaginaries and interventions are only one part of broader civil society strategies and contested politics of data - that may jointly challenge the dominant corporate visions. In the long run they can constitute a small building block in articulating and enacting more beneficial digital futures for the many, not the few.

Annette Markham's contribution in turn shows how hard it is to challenge dominant narratives and their taken-for-grantedness. In her public engagement experiments called The Museum of Random Memory (MoRM), the author specifically pinpoints the power of the theme of inevitability. These experiments show that even as participants began to think more critically about digital platforms, it seemed hard for them to not reproduce current ideological trends or to cede control to external, often corporate stakeholders. In Markham's analysis this is the result of companies' very successful "discursive closure" that naturalizes, neutralizes and legitimizes the specific and contingent values and infrastructures of today's networks, closing off discussion of alternatives that might counter current hegemonic power. Consequently, the author is planning to use more direct critique of current trajectories and the notion "aspiration", rather than "imagination", in their future interventions to help participants "think entirely otherwise".

In the concluding essay, Sally Wyatt reminds us of the importance of our own choice of words as researchers in imagining and creating alternative digital futures. Revisiting her own work on metaphors of the internet and analyzing current nature-related metaphors including "cloud computing" and "big data as new oil" the author focuses on the responsibilities of critical scholars of the internet and new media to be vigilant about their own metaphorical language. Arguing that metaphors are not only descriptive, but carry a normative dimension the author concludes with a plea for moving beyond deconstructing the metaphors of others and creating new metaphors and new ways of thinking about the future.

\section{Conclusion - The politics of digital futures}

As a number of contributions in this special issue show, corporate future imaginaries travel, translate into and gain ground in local contexts, social practices and even people's mind. Annette Markham pinpoints this pervasive influence with the notion of "inevitability". This indicates that technology companies not only take over the imaginative power of shaping future society from state actors, but partly also their ability to govern these very futures with their rhetoric, technologies and business models. In this sense, this special issue may also be seen as extending research on the ongoing privatization of internet governance through modes of private ordering, lobby attempts and mundane practices (Gillespie 2018; Hofmann et al 2017; Klonick 2018; Mager 2018). As it appears, the making and governing of digital technology are not two separate spaces and sets of practices, as we meant to reference in the title of this special issue. Most notably, much of the governing of digital technology seems to be executed in the making of digital technology and its rhetoric. 
Beyond the cases in this collection of articles, we can currently observe this phenomenon in the debate on "Artificial Intelligence" (AI). While tech companies' strong discursive and technological clutch to shape and govern future developments is evident in the case of platforms (Gillespie 2010; Poell et al 2019), it is becoming increasingly relevant in the intense debate about AI. Despite critics' fear that AI will eliminate democratic societies and the autonomy of humans, proponents position AI technologies as a means to fix fundamental problems of our societies: the promise of accident-free autonomous vehicles, automated detection of illnesses, automatic filtering of misinformation and hate speech to name but a few examples. These utopian visions of the future are strongly spearheaded by the same "big five" corporations Apple, Amazon, Google, Facebook, Microsoft - that currently drive and dominate most digital markets (Dolata 2017). With that move, they claim to take on challenges and issues usually tackled and governed by state actors and public institutions - while pursuing their own business interests.

More broadly, the current hype seems to suggest that AI is inevitable and that it will fundamentally change how we live, communicate, work and travel. While these claims are clearly the product of a contingent hype, they nevertheless have powerful effects in how they structure actors and resources. The few studies that exist show that media representation of AI is strongly dominated by corporate actors and products today (Brennan et al 2018; Chuan et al. 2019), while it was more about research in earlier phases of interest in AI (Fast/Horvitz 2017; Katzenbach et al. 2020). Even in governmental regulations and national AI strategies, the industry's narrative of inevitability of AI as a key technology that will necessarily become a central sociotechnical institution is the dominant imaginary (Katzenbach/Bareis 2019). In that way, technology companies are shaping futures. The vast "interpretative flexibility" (Pinch and Bijker 1987) of vague and contested terms such as AI are increasingly becoming filled with specific meanings that meet corporate interests - instead of alternative options. These, in turn, influence the plurality of technological options, struggles and possible trajectories encapsulated under this umbrella term (Cardon et et. 2018) and guide the formation of $21^{\text {st }}$ century AI. Hence, these influential corporations steer the making and governing of digital technology both with their products and with their prophecies.

This increasing influence of corporate sociotechnical imaginaries on society and policy has significant implications for the future of democracy. As future imaginaries settle in technology, infrastructure and daily routines they unfold their capacity to redefine the very nature of privacy, democracy and the self (Cohen 2012). Cohen (2013: 1913) argues that networked information technologies "mediate our experiences of the world in ways directly related to both the practice of citizenship and the capacity for citizenship, and so they configure citizens as directly or even more directly than institutions do." At the same time, these companies have neither been elected, nor are they democratically legitimized, as a member of the European Parliament argued. This EP member frames Silicon Valley companies like Google as "exterritorial agency shaping future developments without any democratic legitimacy, without any accountability to citizens." (anonymized interview quoted in Mager 2018: 3666). Since networked information technologies have the capacity to contribute to or prevent „citizens' capacity for democratic self-government" (Cohen 2013: 1912), Cohen concludes that ownership, transparency and accountability of networked technologies are necessary ingredients for democratic societies.

Thus, political orders and technologies are always co-produced, as captured with the notion of sociotechnical imaginary. At the same time, these futures are often commodified as they are enacted and performed by hegemonic technology companies and their expanding infrastructures, services and products. As a response to their hegemonic position in imagining and shaping future society, we may start thinking about ways of strengthening alternative technologies and their visions of the future. Despite their creativity to come up with alternative 
technologies and future visions, civil organizations, activists and researchers seem to have a hard time asserting their imaginaries against dominant visions and versions of future society, as a number of contributions of this special issue show (Kazansky/Milan, Markham). Accordingly, we have to ask how to support counter-imaginaries and civic technologies and turn their "vanguard visions" (Hilgartner 2015) into collectively held sociotechnical imaginaries traveling and settling beyond their own communities. We hope that this special issue has taken a first step towards this ambitious goal by showing how dominant future imaginaries emerge and spread, how they compete with alternative visions, and what mechanisms prevent counter-imaginaries from proliferating. How to intervene in these dynamics and contribute to more open, democratic and sustainable digital futures will be a key question to be addressed in future research and political action. 


\section{References}

Barker J (2015) Guerilla Engineers: The Internet and the Politics of Freedom in Indonesia. In: Jasanoff S and Kim S-H (eds) Dreamscapes of Modernity: Sociotechnical Imaginaries and the Fabrication of Power. Chicago/London: University of Chicago Press, pp. 199-218. DOI: 10.7208/chicago/9780226276663.001.0001.

Barry A (2001) Political Machines. Governing a Technological Society. London/ New York: The Athlone Press.

Barry A (2006) Technological Zones. European Journal of Social Theory 9(2): 239-253.

Brennen JS, Howard PN and Nielsen RK (2018) An Industry-Led Debate: How UK Media Cover Artificial Intelligence. Reuters Institute for the Study of Journalism: Factsheet December 2018.

Brown N and Michael M (2003) A Sociology of Expectations: Retrospecting Prospects and Prospecting Retrospects. Technology Analysis \& Strategic Management 15 (1): 3-18.

Brown N, Rappert B and Webster A (eds.) (2000) Contested Futures. A sociology of prospective techno-science. Burlington: Ashgate.

Cardon D, Cointet J-P and Mazières A (2018) Neurons spike back: The Invention of Inductive Machines and the Artificial Intelligence Controversy. Réseaux 211(5): 173. DOI: 10.3917/res.211.0173.

Chuan C-H, Tsai W-HS and Cho SY (2019) Framing Artificial Intelligence in American Newspapers. In: Proceedings of the 2019 AAAI/ACM Conference on AI, Ethics, and Society AIES '19, Honolulu, HI, USA, 2019, pp. 339-344. ACM Press. DOI: $\underline{10.1145 / 3306618.3314285 .}$

Cohen JE (2012) Configuring the Networked Citizen. In Sarat A, Douglas L and Umphrey MM (eds) Imagining New Legalities: Privacy and Its Possibilities in the 21st Century. Standford, CA: Standford University Press: 129-53.

Cohen JE (2013) What privacy is for? Harvard Law Review 126: 1904-1933

Dolata U (2017) Apple, Amazon, Google, Facebook, Microsoft. Market Concentration Competition - Innovation Strategies. SOI Discussion Paper 2017-01. Stuttgart: Institute for Social Sciences.

Fast E and Horvitz E (2017) Long-Term Trends in the Public Perception of Artificial Intelligence. Proceedings of the Thirty-First AAAI Conference on Artificial Intelligence (AAAI17).

Felt U and Öchsner S (2019) Reordering the "World of Things": The Sociotechnical Imaginary of RFID Tagging and New Geographies of Responsibility, Science and Engineering Ethics 25: 1425-1446.

Flichy P (2007) The Internet Imaginaire. Cambridge, MA: MIT Press.

Gillespie T (2010) The politics of 'platforms'. New Media \& Society 12: 347-364. DOI: $10.1177 / 1461444809342738$.

Gillespie T (2018) Custodians of the Internet. Platform, Content Moderation, and the Hidden Decisions That Shape Social Media. New Haven: Yale University Press.

Goffman E (1974) Frame analysis: an essay on the organization of experience, Penguin Books 
Hajer MA (2006) Doing discourse analysis - Coalitions, practices, meaning. Words matter in policy and Planning - Discourse Theory and Method in the Social Sciences (pp. 65-74) (10 p.). KNAG.

Hajer MA (1995) The Politics of Environmental Discourse - Ecological Modernization and the Policy Process. Oxford University Press, Oxford.

Hilgartner S (2015) Capturing the imaginary. Vanguards, visions and the synthetic biology revolution. In S Hilgartner, C Miller and R. Hagendijk (eds) Science and Democracy. Making Knowledge and Making Power in the Biosciences and Beyond. London: Routledge: 33-55.

Hofmann J, Katzenbach C and Gollatz K (2017) Between coordination and regulation: Finding the governance in Internet governance. New Media \& Society 19(9): 1406-1423. DOI: $10.1177 / 1461444816639975$.

Jasanoff S and Kim SH (2015) Dreamscapes of Modernity: Sociotechnical Imaginaries and the Fabrication of Power. Chicago, IL: University of Chicago Press.

Jasanoff S and Kim SH (2009) Containing the Atom: Sociotechnical Imaginaries and Nuclear Power in the United States and South Korea. Minerva 47:119-146.

John N (2013) Sharing and Web 2.0: The emergence of a keyword. New Media \& Society 15(2). 167-182. DOI: $10.1177 / 1461444812450684$.

John N (2017) Sharing - from ploughshares to file sharing and beyond. In: HIIG | Digital Society Blog. Available at: https://www.hiig.de/en/sharing-from-ploughshares-to-file-sharingand-beyond/ (accessed 25 February 2020).

Katzenbach C (2019) AI will fix it. In: Kettemann M and Dreyer S. (Eds.) Busted! The Truth About the 50 Most Common Internet Myths. Hamburg: Hans-Bredow-Institut.

Katzenbach C and Bareis J (2019) Talking AI into Being: The Imaginaries of National AI Strategies and their Performative Politics. Paper presented at IAMCR 2019. DOI: 10.5281/zenodo.3678145.

Katzenbach C and Larsson S (2017) Imagining the Digital Society - Metaphors from the Past and Present. HIIG | Digital Society Blog. Dossier. Available at: https://www.hiig.de/en/imagining-the-digital-society-metaphors-from-the-past-and-present/ (February 25, 2020).

Katzenbach C et al. (2020) Künstliche Intelligenz im Spiegel der Zeit. Die Darstellung von KI im SPIEGEL von 1970-2018. In: Schwarzenegger C, Pentzold C, Birkner T, and Katzenbach C (Eds.) Digitale Kommunikation und Kommunikationsgeschichte. Berlin: Deutsche Gesellschaft für Publizistik- und Kommunikationswissenschaft.

Kim SH (2015) Social Movements and Contested Sociotechnical Imaginaries in South Korea. In: Jasanoff S and Kim SH (Eds.) Dreamscapes of Modernity. Sociotechnical Imaginaries and the Fabrication of Power. Chicago/London: University of Chicago Press, pp. 152-173.

Klonick K (2018) The New Governors: The People, Rules, and Processes Governing Online Speech. Harvard Law Review 131: 1598-1670.

Lakoff G and Johnson M (1980) Metaphors we live by. Chicago \& London: The University of Chicago Press.

Lehtiniemi T and Ruckenstein M (2019) The social imaginaries of data activism. Big Data \& Society, SAGE PublicationsSage UK: London, England 6(1): 205395171882114.

Mager A (2017) Search engine imaginary. Visions and values in the co-production of search technology and Europe.Social Studies of Science47(2): 240-262. 
Mager A (2018). Internet governance as joint effort: (Re)ordering search engines at the intersection of global and local cultures. New Media \& Society, 20(10), 3657-3677.

Mosco V (2005) The Digital Sublime (MIT Press): Myth, Power, and Cyberspace. New Ed. Cambridge, Mass.: MIT Press.

Mansell R (2012) Imagining the Internet: Communication, Innovation, and Governance. Oxford: Oxford University Press.

Olbrich P and Witjes N (2016) Sociotechnical Imaginaries of Big Data: Commercial Satellite Imagery and Its Promise of Speed and Transparency. In: Bunnik A, Cawley A, Mulqueen M, et al. (eds), Big Data Challenges, London: Palgrave Macmillan UK, pp. 115-126.

Pinch T and Bijker W (1987) 'The social construction of facts and artifacts: or howthe sociology of science and the sociology of technology might benefit eachother', in The Social Construction of Technological Systems. New Directions in the Sociology and History of Technology, eds W. Bijker, T. Hughes \& T. Pinch, MITPress, Cambridge, MA, pp. 17-50.

Poell T, Nieborg D and Dijck J van (2019) Platformisation. Internet Policy Review 8(4). Available at: https://policyreview.info/concepts/platformisation (accessed 21 February 2020).

Rieder G (2018) Tracing big data imaginaries through public policy: The case of the European Commission. In: Sætnan A, Schneider I and Green N (eds) The Politics of Big Data. London: Routledge.

Srnicek N (2016) Platform Capitalism. London: Wiley.

Taylor C (2004) Modern Social Imaginaries. Durham: Duke University Press.

Turner F (2006). From Counterculture to Cyberculture: Stewart Brand, the Whole Earth Network, and the Rise of Digital Utopianism. University of Chicago Press.

Van Lente H and Rip A (1998) Expectations in Technological Developments: An Example of Prospective Structures to be Filled in by Agency. In: Disco C , Meulen Bvd (eds.) Getting New Technologies Together. Studies in Making Sociotechnical Order. Berlin, Boston: De Gruyter, 203-230.

Van Lente H (2012), Navigating Foresight in a Sea of Expectations: Lessons from the Sociology of Expectations, Technology Analysis \& Strategic Management, Vol. 24, No. 8, 789802

Wyatt S (2004) Danger! Metaphors at Work in Economics, Geophysiology, and the Internet, Science, Technology \& Human Values 29(2):242-261

\footnotetext{
https://medium.com/blockchain/the-wait-is-over-buy-sell-is-coming-to-america-855e91fa775c $\quad$ (accessed February 2020)

ii https://siliconvalley.tours/profile/waymo/ (accessed 25 February 2020)

iii $\quad$ https://ec.europa.eu/info/aid-development-cooperation-fundamental-rights/your-rights-eu/know-yourrights/freedoms/protection-personal-data en (accessed 25 February 2020)
} 